\title{
Research progress of key technologies for preparing concrete ad- mixtures by multiple activation of iron-containing tailings
}

\author{
Xiaowei $\mathrm{Gu}^{1}$, Ziyang $\mathrm{Hu}^{2}$, Peng $\mathrm{Liu}^{2 *}$, Shuyun Pang ${ }^{2}$, Haofeng $\mathrm{Chi}^{2}$ \\ ${ }^{1}$ Northeastern University, Shenyang, Liaoning, China \\ ${ }^{2}$ Department of Architecture and Civil Engineering, Shenyang University of Technology, Shenyang, Liaoning, China
}

\begin{abstract}
Iron tailings are an excellent secondary resource. Reasonable use, it can not only alleviate the problem of resource shortage, but also solve some environmental pollution problems. Therefore, it has a good development prospect. The resource utilization of iron tailings has always been a hot spot of social concern. The article reviews the results achieved by the predecessors. In addition, outlines the method of activation of iron tailings and the influence of its strength and durability as a concrete composite admixture. At last, the prospects of the research on the utilization of iron tailings are put forward.
\end{abstract}

\section{Introduction}

Iron tailings are industrial solid wastes produced after iron ore is processed, refined and sorted. At present, most iron ore companies choose to stack a larger part of the tailings for backfilling treatment, and only a small part is used. According to statistics, iron tailings in my country the comprehensive utilization rate is only $11.27 \%{ }^{[1]}$. Not only occupy space and waste land resources, but also cause environmental pollution. China has rich iron ore resources. As of the end of $2011^{[2]}, 4,011$ iron ore mines have been identified nationwide, with reserves of 5.667 billion tons, and basic reserves of 19.276 billion tons. Stone resource reserves are 74.39 billion tons. By 2011, china has 4203 mines, the amount of rough iron ore mined reached 1.327 billion tons. It is conceivable that the iron tailings produced are even more astronomical. At the same time, the Chinese economy is booming, industrialization and urbanization continue to advance, the demand for steel continues to increase. It is foreseeable that a large amount of iron tailings will be produced in the future.

After entering the 21 st century, the effective utilization of resources appears to be particularly important, the secondary utilization of iron tailings is even more important. In order to solve the above problems, the comprehensive utilization of iron tailings ${ }^{[3]}$ and increasing its utilization rate have become a research hotspot in recent years. The multiple activation of iron-containing tailings as admixtures to prepare concrete is one of the effective ways of resource utilization of iron tailings. In recent years, domestic and foreign scholars have conducted continuous research on this and have achieved certain results. The article summarizes and looks forward to the method of activation of iron tailings and its influence on the strength and durability of concrete as a composite admixture.

\section{Iron tailings activation method}

Iron tailings are divided into monometallic iron tailings and polymetallic iron tailings, whether they are Anshan high-silicon type iron tailings or Maanshan Iron and Steel high-alumina type iron tailings. These tailings are inherently inert and must be modified to stimulate their activity if they want to be used. At present, there are various activation methods, which can be activated by mechanical force, chemical activation, thermal activation ${ }^{[4]}$, etc.

\subsection{Mechanical activation of iron tailings}

In 2002, Shujun $\mathrm{Gao}^{[5]}$ et al. selected three iron tailings in Nanjing, Maanshan and Meishan. ND2 type planetary ball mill is used for grinding, the particles are squeezed each other through mechanical force, shear force and grinding action. Furthermore, the inside of the tailings particles is depolymerized, cracks are formed on the surface and inside of the particles, the material composition is gradually uniform, so that some polar molecules or ions that can decompose the slag enter the inside, improve the activity of the tailings. The strength of concrete made with different grinding time and different age of mineral particles. The results show that the best grinding for 2-4 hours can increase the compressive strength by 1.5 to 7 times. At the same time, it was discovered during the grinding process that there is a limit to the fineness of the particle, otherwise agglomeration will occur ${ }^{[6]}$ and the specific surface area will decrease instead.

In 2013, Mengyi Chen ${ }^{[7]}$ et al. selected some iron ore tailings in Hubei. Using a $5 \mathrm{~kg}$ small ball mill, mechanical

\footnotetext{
* Corresponding author: pliu@sut.edu.cn
} 
force is used to distort the crystal lattice of the iron tailing crystals, reduce the degree of crystallinity, change its microstructure, increase the activity of the iron tailings. The mortar strength test was carried out on the iron tailings powder. The compressive strength of tailings powder with different fineness, different blending amount and different curing conditions was measured. The results show that the sand activity index is $69 \%$ when the specific surface area is $751 \mathrm{~m}^{2} / \mathrm{kg}$. The strength contributions of tailings powder blended with $20 \%$ of this fineness under autoclave curing for 3, 28, and 56 days are 14.02, 20.08, and 22.86 $\mathrm{MPa}$, respectively.

In 2014, Chaomei Meng ${ }^{[8]}$ et al. selected a high silicon iron tailings in Liaoning Province. Using the SYM-cement ball mill, through different grinding time, it is found that the grinding process can be roughly divided into three stages: first the tailings particles are broken and the specific surface area of the material increases; then aggregation occurs and the free energy decreases; finally the tailings particles agglomerate Phenomenon; the final result shows that the tailings particles have the best activity after 3.5 hours of grinding, the $30 \%$ of the tailings powder is added to the cement mortar test. The $28 \mathrm{~d}$ compressive strength is greatly improved, can be used as a concrete cementing material to prepare concrete.

In 2016, Chunai Piao ${ }^{[9]}$ et al. selected an iron tailings in Qian'an, Hebei. Using a $5 \mathrm{~kg}$ laboratory ball mill, the effects of different grinding times on the specific surface area, density, particle size and microstructure of iron tailings particles were studied. Through orthogonal solidification, the results show that as the grinding time of iron tailings increases, the particle density first decreases and then increases, the specific surface area first increases and then decreases, the grinding time is 2 hours, the density is the smallest, which is $2.75 \mathrm{~g} / \mathrm{m}^{3}$, the specific surface area is $770 \mathrm{~m}^{2} / \mathrm{kg}$. According to the activity study and IR analysis, the compressive strength and activity index of the tailings particles at different ages are all maximum.

In 2017, Fahai Zhang ${ }^{[10]}$ et al. selected a certain subway tailings. Use a $0.08 \mathrm{~mm}$ square hole sieve for sieving, then use a laboratory ball mill to grind, control different grinding times, orthogonally compare the results, and perform electron microscope analysis, X-ray diffraction analysis, infrared spectrum and intensity analysis at the same time. The results show that with the lengthening of the grinding time, the absorption capacity of the English band of the tailings is strengthened and the degree of activation is deepened; under different grinding times, the siliconoxidation bond in the tailings will be broken and reorganized, which improves its activity.

In 2020, Xiaowei Cui ${ }^{[11,12]}$ and others selected skarn iron tailings in Shangluo City, Shaanxi Province. Use DHG-9075A electric heating blast drying oven to control the water content within $1 \%$, use a laboratory grinder to grind for $60 \mathrm{~min}, 80 \mathrm{~min}, 100 \mathrm{~min}, 120 \mathrm{~min}$. The specific surface area tester, X-ray diffractometer, American Fourier infrared spectrometer, thermal analyzer were used to analyze the influence of grinding time on tailings particles. The results show that mechanical force can destroy the internal structure of iron tailings, break chemical bonds, increase defects, improve activity. However, the agglomeration phenomenon still needs attention, the grinding time is controlled at $100 \mathrm{~min}$, which is more suitable for higher activity index.

Recent years, the research on the activation of iron tailings by mechanical force has been continuously deepened, and the mechanism of mechanical force activation has gradually become clear. As a result, relatively suitable grinding fineness, specific surface area, and grinding time have been obtained. However, further research is needed to utilize iron tailings in the project.

Table 1 Summary of existing research on mechanical activation of iron tailings

\begin{tabular}{|c|c|c|c|c|}
\hline years & scholar & Tailings Origin & Test equipment & Results \\
\hline 2002 & Shujun $\mathrm{Gao}^{[5]}$ & Nanjing etc. & ND2 ball mill & $\begin{array}{l}\text { The best activity in } 2 \sim 4 \mathrm{~h} \text {, the compres- } \\
\text { sive strength increased by } 1.5 \sim 7 \text { times }\end{array}$ \\
\hline
\end{tabular}

\begin{tabular}{|c|c|c|c|c|}
\hline 2013 & Mengyi Chen ${ }^{[7]}$ & Hubei & $5 \mathrm{~kg}$ small ball mill & $\begin{array}{l}\text { When the specific surface area is } \\
751 \mathrm{~m}^{2} / \mathrm{kg} \text {, the activity index is } 69 \%\end{array}$ \\
\hline 2014 & Chaomei Meng ${ }^{[8]}$ & Liaoning & SYM-Cement Ball Mill & $3.5 \mathrm{~h}$ best activity \\
\hline 2016 & Chunai Piao ${ }^{[9]}$ & Qian'an, Hebei & $5 \mathrm{~kg}$ laboratory ball mill & $2 \mathrm{~h}$ best activity \\
\hline 2017 & Fahai Zhang ${ }^{[10]}$ & & $5 \mathrm{~kg}$ laboratory ball mill & Increased activity \\
\hline 2020 & Xiaowei Cui ${ }^{[11,12]}$ & Shaanxi & $5 \mathrm{~kg}$ laboratory ball mill & High activity index in $100 \mathrm{~min}$ \\
\hline
\end{tabular}

\subsection{Chemically activated iron tailings}

In 2008, Yongchao Zheng ${ }^{[13]}$ and others selected Beijing Miyun iron tailings, cement clinker, slag, desulfurization gypsum, diagenetic agents. The iron tailings are classified and screened to obtain particles with a particle size of less than $50 \mu \mathrm{m}$, mixed with cement clinker and desulfurized gypsum to an average particle size of $5 \mu \mathrm{m}$. The coarse aggregate with a particle size greater than $50 \mu \mathrm{m}$ is mixed with a diagenetic agent, cured for 1 day at room temperature and relative humidity at $90 \%$, then the mold is removed, and then cured by steam. The results show that the activity of tailings is improved through chemical activation. The composition of raw materials, the amount of diagenetic agent and curing conditions will affect the performance of the material. At last, a high-strength material with a strength greater than $100 \mathrm{MPa}$ was successfully prepared. The mixing amount of tailings reaches $70 \%$, the total solid waste usage reaches $87 \%$.

In 2010, Dezhong Li ${ }^{[14]}$ et al. selected Beijing Miyunshou iron and steel tailings, cement clinker, blast furnace 
slag, desulfurization gypsum, and water reducer. Use WL1 ball mill to feed $5 \mathrm{~kg}$ each time for classifying grinding. The tailings are ground in the first stage, blast furnace slag is added in the second stage, water reducing agent and gypsum are added in the third stage to obtain a mixture. Orthogonal experiment discusses the mild influence factors of the mixture specimen. The results show that the mixing time of $60 \mathrm{~min}$, the water reducing agent content of $1 \%$, the tailing particle size of $0.16 \sim 2.5 \mathrm{~mm}$ are reasonable. The $28 \mathrm{~d}$ compressive strength of the obtained concrete is 97.63MPa.

In 2013, Anling Wang ${ }^{[15]}$ et al. iron tailings in Qian'an, Hebei. Use a ball mill to grind to a fineness of $430 \mathrm{~kg} / \mathrm{m}^{2} \pm 20 \mathrm{~kg} / \mathrm{m}^{2}$, mix with slag powder in different proportions. Orthogonal experiment analysis results explore the effect of fineness on activity. The results showed that the activity of the mixture was improved, the activity increased by about $15 \%$ to $35 \%$ in 28 days. It proves that the composite effect of iron tailings powder and slag powder is good, the research on preparing concrete can be carried out.

In 2015, Beixing $\mathrm{Li}^{[16]}$ et al. selected Beijing Miyun iron tailings, Huaxin Cement, Guizhou Hongfu phosphorous slag, limestone, dihydrate gypsum, and triethanolamine as a grinding aid. Use a $5 \mathrm{~kg}$ laboratory ball mill for step grinding. The specific steps are shown in Figure 1. The results show that the iron tailings-phosphorus slagbased composite admixture (TPCMA) improves the volatilization activity of the mixture during the hydration process through the refinement of the phosphorus slag. When the effective mixing time $\mathrm{Q}=42.5 \mathrm{~min}$, the overall uniformity of TPCMA is better, at the same time the activity index can reach $82 \%$. At the same time, the mixture can produce a large amount of calcium silicate hydrate $(\mathrm{CSH})$ and ettringite under the action of calcium hydroxide and gypsum, showing a certain strength.

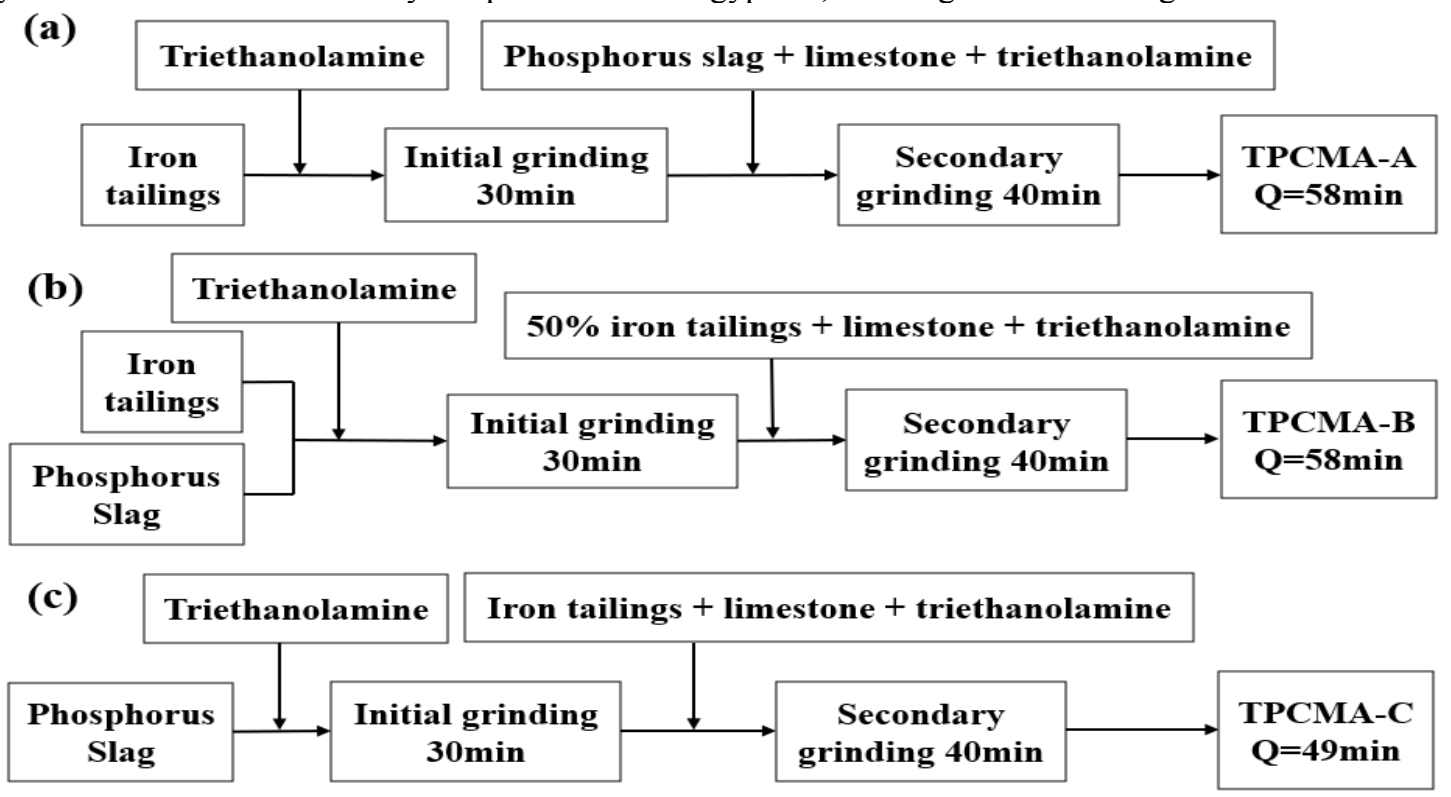

Figure 1 Flow chart of different cascade grinding sequence ${ }^{[16]}$

In 2016, Chunai Piao ${ }^{[17]}$ et al. selected iron tailings in hydration. The results are measured through orthogonal Qian'an, Hebei. Use P I 42.5 cement and some water reducing agents including $\mathrm{Na}_{2} \mathrm{SiO}_{3}, \mathrm{NaOH}, \mathrm{Na}_{2} \mathrm{SO}_{4}$, $\mathrm{CaSO}_{4} 2 \mathrm{H}_{2} \mathrm{O}$, the purity of which is greater than or equal to $96 \%$. Use a $5 \mathrm{~kg}$ ball mill to grind the mixture into different finenesses. Carry out electron microscope analysis, infrared spectroscopy analysis, and test the heat of experiments. The results show that: when the ball mill is pulverized for 2 hours and the $\mathrm{CaSO}_{4} 2 \mathrm{H}_{2} \mathrm{O}$ content is $0.5 \%$, the internal disordered matter increases, at the same time the iron tailings have better activity. The flexural strength and activation index are the maximum at the age of 7, 28 days.

Table 2 Summary of existing research on chemically activated iron tailings

\begin{tabular}{|c|c|c|c|c|}
\hline years & scholar & Tailings Origin & Supplementary materials & Results \\
\hline 2008 & Yongchao Zheng ${ }^{[13]}$ & Miyun, Beijing & $\begin{array}{c}\text { Cement clinker, slag, desulfurization gypsum, } \\
\text { diagenetic agent }\end{array}$ & $\begin{array}{l}\text { Material strength is } \\
\text { greater than } 100 \mathrm{MPa}\end{array}$ \\
\hline 2010 & Dezhong Li ${ }^{[14]}$ & Miyun, Beijing & $\begin{array}{l}\text { Cement clinker, blast furnace slag, desulfuri- } \\
\text { zation gypsum, water reducing agent }\end{array}$ & $\begin{array}{l}28 \mathrm{~d} \text { compressive } \\
\text { strength is } 97.63 \mathrm{MPa}\end{array}$ \\
\hline 2013 & Anling Wang ${ }^{[15]}$ & Qian'an, Hebei & Slag powder & $\begin{array}{l}\text { Increase activity by } \\
\text { about } 15 \% \sim 35 \%\end{array}$ \\
\hline 2015 & Beixing Li ${ }^{[16]}$ & Miyun, Beijing & $\begin{array}{l}\text { Cement, phosphorous slag, limestone, dihy- } \\
\text { drate gypsum, triethanolamine }\end{array}$ & $\begin{array}{l}\text { Activity index reaches } \\
82 \%\end{array}$ \\
\hline 2016 & Chunai Piao ${ }^{[17]}$ & Qian'an, Hebei & $\begin{array}{l}\mathrm{P} \cdot \mathrm{I} 42.5 \text { cement and some water reducers in- } \\
\text { clude } \mathrm{Na}_{2} \mathrm{SiO}_{3}, \mathrm{NaOH}, \mathrm{Na}_{2} \mathrm{SO}_{4}, \mathrm{CaSO}_{4} \cdot 2 \mathrm{H}_{2} \mathrm{O}\end{array}$ & $\begin{array}{l}\text { Increased iron tailing } \\
\text { activity }\end{array}$ \\
\hline
\end{tabular}




\subsection{Thermally activated iron tailings}

In 2007, Xiangpeng Feng ${ }^{[18]}$ et al. selected an iron tailing in Tonghua, Jilin. The Suzhou pure kaolin and tailings were mixed and wet milled at a ratio of $1: 1$ for 0.5 hours, then dried, and then calcined at a high temperature of $600^{\circ} \mathrm{C}$ for 2 hours. The mixed materials with different dosages were subjected to the mortar strength experiment, the $28 \mathrm{~d}$ strength was measured. The results are shown in Table 1. The results show that through wet grinding and mixing and calcination, the tailings react during the heating and dehydration process, the structure is distorted, the activity and the reaction performance are improved. When the mixture content is $50 \%$, the strength of $28 \mathrm{~d}$ mortar can reach $29.4 \mathrm{MPa}$.

Table 3 Strength test results of wet grinding kaolin-iron tailing mixture mortar ${ }^{[18]}$

\begin{tabular}{cccccc}
\hline \multirow{2}{*}{ Numbering } & $\begin{array}{c}\text { Wet grinding tailings } \\
\text { mixture (\%) }\end{array}$ & \multicolumn{2}{c}{ Flexural strength/MPa } & \multicolumn{2}{c}{ Compressive strength/MPa } \\
\cline { 3 - 5 } & & $3 \mathrm{~d}$ & $28 \mathrm{~d}$ & $3 \mathrm{~d}$ & $28 \mathrm{~d}$ \\
\hline E1 & 40 & 3.9 & 7.8 & 10.3 & 33.6 \\
E2 & 50 & 3.3 & 7.3 & 9.2 & 29.4 \\
E3 & 55 & 2.6 & 5.9 & 7.8 & 24.8 \\
E4 & 60 & 2.1 & 5.7 & 7.4 & 19.3 \\
\hline
\end{tabular}

In 2009, Zhonglai $\mathrm{Yi}^{[19]}$ et al. selected Gushan iron tailings in Maanshan, Anhui. The tailings are dried at $100^{\circ} \mathrm{C}$, and then thermally activated at different temperatures, at last the activated tailings are ground to a specific surface area of $400 \mathrm{~m}^{2} / \mathrm{kg}$. The phase change was analyzed by differential thermal analysis (DTA) and thermogravimetry (TG), the strength was tested by the mortar strength test. The results show that the kaolinite in the tailings decomposes during the thermal activation process. After complete decomposition, the activity index reaches the highest. After heating continues, the $\mathrm{CaO}$ produced by the decomposition of calcite will react with the $\mathrm{SiO}_{2}$ and $\mathrm{Al}_{2} \mathrm{O}_{3}$ produced by the decomposition of kaolin, and the activity will decrease. Therefore, $700^{\circ} \mathrm{C}$ thermal activation is the best value. At this time, when the tailings content is $30 \%$, the

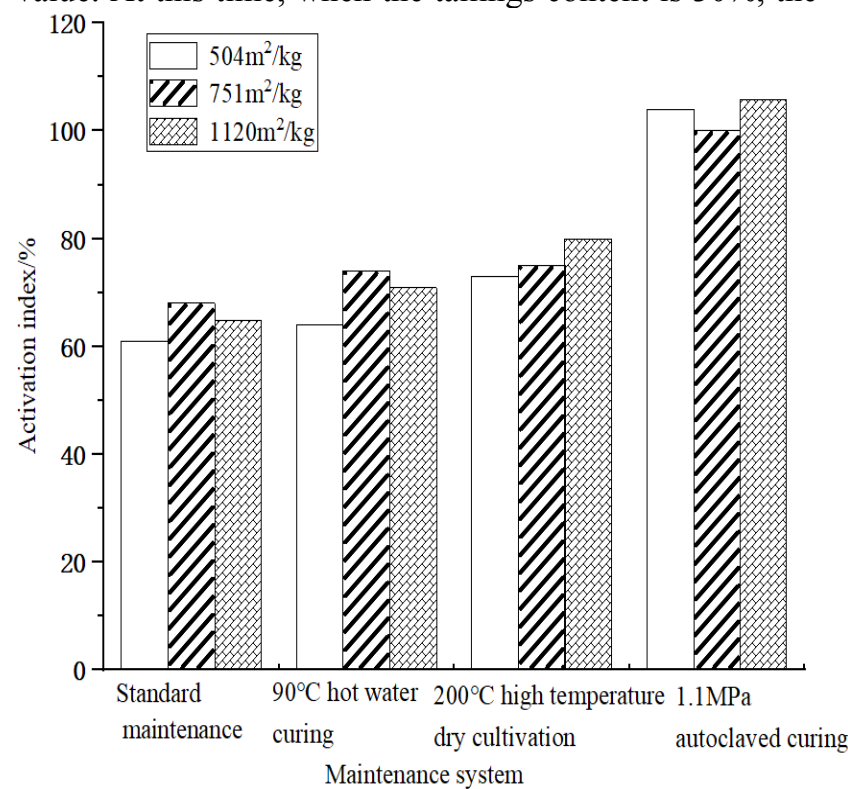

Figure 2 The effect of maintenance system on

In 2015, Ankang Song ${ }^{[21]}$ et al.selected an iron tailing with kaolinite as the main component. The iron tailings are made into strips with a diameter of $5 \mathrm{~mm}$, dried at $105^{\circ} \mathrm{C}$, calcined in a muffle furnace at a certain temperature. After holding for a certain period of time, they are removed and ground to test the activity index. The comparison results strength of $28 \mathrm{~d}$ mortar can reach $40.3 \mathrm{MPa}$.

In 2013, Beixing $\mathrm{Li}^{[20]}$ et al. selected a certain siliconrich iron tailings. Use a laboratory standard ball mill to grind to obtain iron tailings powder with different finenesses, compare the activity index and cement mortar strength under different curing conditions through orthogonal experiments. The results show that the tailings activity is not high under standard curing, $90^{\circ} \mathrm{C}$ hot water curing, and $200^{\circ} \mathrm{C}$ high temperature dry heat curing. Under autoclave curing, the activity is higher, with $504 \mathrm{~m}^{2} / \mathrm{kg}$, $751 \mathrm{~m}^{2} / \mathrm{kg}, 1120 \mathrm{~m}^{2} / \mathrm{kg}$. The specific results of different specific surface areas of are shown in Figure 2. At the same time, $\mathrm{SiO}_{2}$ reacts with $\mathrm{Ca}(\mathrm{OH})_{2}$ to produce gelling substances, which further improves the strength.

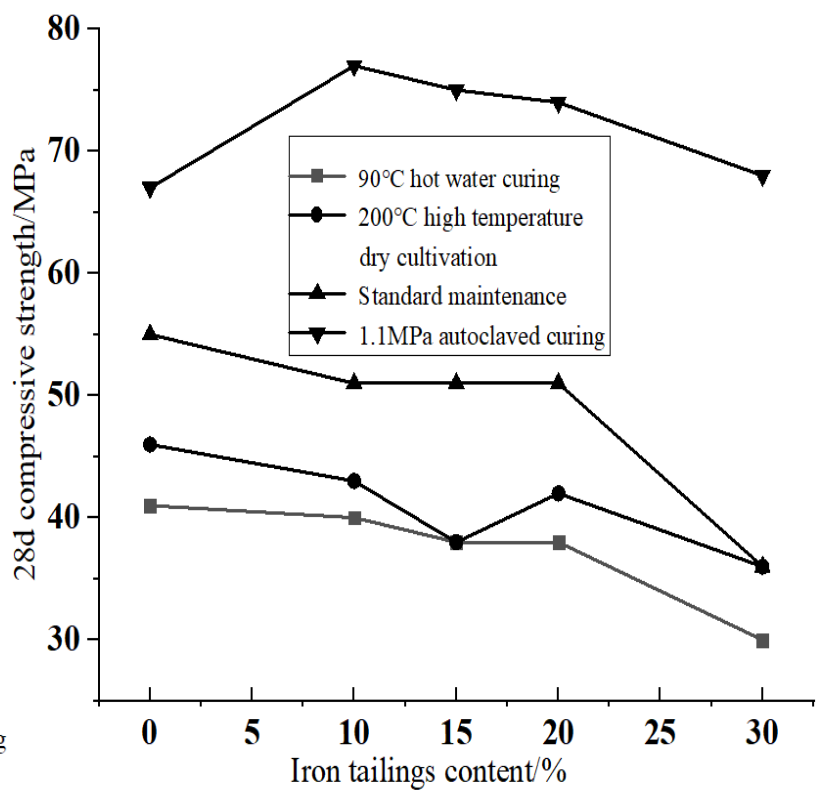

activity index and compressive strength ${ }^{[20]}$

of orthogonal experiments show that the tailings activity is higher when calcined at $700{ }^{\circ} \mathrm{C}$ for $1 \mathrm{~h}$ and $800{ }^{\circ} \mathrm{C}$ for $0.5 \mathrm{~h}$, the activity index is $122 \%$. It is more suitable that the particle size is less than $12 \mu \mathrm{m}$. It shows that the tailings can produce pozzolanic activity when calcined, and it is a good admixture for preparing concrete. 
Table 4 Summary of existing research on thermally activated iron tailings

\begin{tabular}{|c|c|c|c|c|}
\hline years & scholar & Tailings Origin & experiment procedure & Results \\
\hline 2007 & Xiangpeng Feng ${ }^{[18]}$ & Jilin Tonghua & $\begin{array}{l}\text { Mixed and wet milled for } 0.5 \text { hours, } \\
\text { dried, then calcined at a high temperature } \\
\text { of } 600^{\circ} \mathrm{C} \text {, kept for } 2 \text { hours }\end{array}$ & Strength up to $29.4 \mathrm{MPa}$ \\
\hline 2009 & Zhonglai $\mathrm{Yi}^{[19]}$ & Maanshan, Anhui & $\begin{array}{l}\text { Drying at } 100^{\circ} \mathrm{C} \text {, heat activation treat- } \\
\text { ment at different temperatures }\end{array}$ & $\begin{array}{c}700^{\circ} \mathrm{C} \text { heat activation } \\
\text { strength can reach } \\
40.3 \mathrm{MPa}\end{array}$ \\
\hline 2013 & Beixing $\mathrm{Li}^{[20]}$ & $\begin{array}{l}\text { A silicon-rich iron } \\
\text { tailings }\end{array}$ & Under different curing conditions & $\begin{array}{c}\text { Under autoclave curing, } \\
\text { higher activity }\end{array}$ \\
\hline 2015 & Ankang Song ${ }^{[21]}$ & $\begin{array}{l}\text { Kaolinite is the } \\
\text { main tailings }\end{array}$ & $\begin{array}{l}\text { Drying at } 105^{\circ} \mathrm{C} \text {, calcining in a muffle } \\
\text { furnace at a certain temperature }\end{array}$ & $\begin{array}{c}\text { Activity index can reach } \\
122 \%\end{array}$ \\
\hline
\end{tabular}

\section{Research on the performance of iron tailings on concrete prepared as admix- tures}

In 2010, Yunhong Cheng ${ }^{[22,23]}$ et al. selected an iron tailing in Liaoning Province. The iron tailing is activated by mechanochemical means, make cementitious materials instead of cements of different specific gravities, as a blending amount to prepare concrete. Carry out concrete carbonization performance test and concrete sulfate corrosion resistance test on the prepared concrete. The results show that the amount of cement replaced by activated tailings is in the range of $10 \%-40 \%$. With the increase of the amount, the carbonization resistance and sulfate corrosion resistance increase. When the replacement cement content is $20 \%, 30 \%$ and $40 \%$, the sulfate corrosion resistance of concrete is higher than the standard. Therefor, from these two levels, it is feasible to use tailings as an auxiliary cementing material to prepare concrete.

In 2015, Wei Zeng ${ }^{[24]}$ et al. used iron tailings as basic materials, composite phosphorous slag and limestone as admixtures for concrete. The prepared C20 C55 concrete was compared with the concrete prepared by mixing II grade fly ash and S95 grade slag powder. The results show that the strength of concrete made with iron tailings is not much different from that with grade II fly ash, which is lower than that with grade S95 slag powder. However, the durability of carbonization resistance, chloride ion penetration resistance and frost resistance are slightly lower than the two.

In 2016, Chunai Piao ${ }^{[25]}$ et al. selected iron tailings in Qian'an, Hebei, used mechanochemical coupling to activate the tailings. Cementitious material containing iron tailings powder is prepared, and then used as admixture to prepare concrete. aiming at affecting the durability and resistance of concrete to chloride ions. The permeability, carbonization resistance, freeze-thaw resistance were studied. The results show that the chemical-mechanical activation of iron tailings has a significant ability to reduce the total porosity and pore connectivity of the hardened mixture, its impermeability is improved compared with blank cement and fly ash. At the same time, the frost resistance of concrete is also good. Its resistance to carbonization is lacking, but the impact is not significant.

Table 5 Summary of existing research on the related properties of concrete prepared from iron tailings

\begin{tabular}{|c|c|c|c|c|}
\hline years & scholar & $\begin{array}{l}\text { Tailings } \\
\text { Origin }\end{array}$ & experiment & Results \\
\hline 2010 & $\begin{array}{l}\text { Yunhong cheng } \\
{[22,23]}\end{array}$ & $\begin{array}{l}\text { Liao- } \\
\text { ning }\end{array}$ & $\begin{array}{l}\text { Carbonization test, sulfate corrosion } \\
\text { resistance test }\end{array}$ & $\begin{array}{l}\text { It is feasible to use tailings } \\
\text { as an auxiliary cementitious } \\
\text { material to prepare concrete }\end{array}$ \\
\hline 2015 & Wei Zeng ${ }^{[24]}$ & & Orthogonal contrast & $\begin{array}{l}\text { Not much difference in in- } \\
\text { tensity }\end{array}$ \\
\hline 2016 & Chunai Piao ${ }^{[25]}$ & $\begin{array}{l}\text { Qian'an, } \\
\text { Hebei }\end{array}$ & $\begin{array}{l}\text { Durability, resistance to chloride ion } \\
\text { permeability, resistance to carboniza- } \\
\text { tion, and freeze-thaw resistance tests }\end{array}$ & $\begin{array}{l}\text { Except for the lack of car- } \\
\text { bonization resistance, other } \\
\text { performances are good }\end{array}$ \\
\hline
\end{tabular}

\section{Summary and Outlook}

Although iron tailings are inherently inert, they can be excited by appropriate methods, such as mechanical activation, chemical activation, and thermal activation, to homogenize the internal results of the tailings, and cause distortions in the internal lattice and occurrence of internal particles. Depolymerization, turning it into an active material similar to natural pozzolanic material. Using iron tailings as an admixture to prepare concrete and even ultra-high performance concrete ${ }^{[26]}$ is one of the reasonable methods for comprehensive utilization of tailings, and it is also an effective way to solve the problem of insufficient resources, which is in line with the development of the society in the new era view. 


\section{References}

1. Wei R. (2014) Research progress in resource utilization of iron tailings[J]. Mining Engineering, 1:56-59.

2. Fan Z. (2013)Research on China's Iron Ore Resource Guarantee Degree[J]. Mining Research and Development, 06:124-126.

3. Cai X. (2000)The progress of iron tailings used as building materials[J]. Metal Mine, 10:45-48.

4. Wang Z. (2017)Pozzolanic activity of tailings and its application in cement mixtures[J]. Bulletin of the Chinese Ceramic Society.

5. Gao S. (2002)Study on the activation of slag by mechanochemical method[J]. Journal of Nanjing University of Technology (Natural Science Edition), 6: 61-65.

6. Li Z. (2005),Agglomeration mechanism of ultrafine powder and its elimination method [J]. Salt Lake Research, 13(001): 31-36.

7. Chen M. (2013)The activity of iron tailings powder and its strengthening effect in concrete[J]. Metal Mine, 05: 170-174.

8. Meng C. (2014)Study on particle size and activity analysis of mechanically activated high-silicon iron tailings[J]. Green Science and Technology, 11:228230.

9. Piao C. (2016)Study on the effect of mechanical activation on the activation performance of iron tailings[J]. Bulletin of the Chinese Ceramic Society, 35: 2973-2979.

10. Zhang F. (2017)Mechanical and chemical activation of iron tailings and preparation of high-strength structural materials[J]. Equipment Manufacturing Technology, 000(012):73-75.

11. Cui X. (2020)Basic research on mechanical grinding characteristics of iron tailings[J]. Nonmetallic Minerals, 043(001):73-75.

12. Cui X. (2014)The influence of steel slag powder on the properties of high-strength tailings concrete[J]. Metal Mine.

13. Zheng Y. (2009)Experimental study on the preparation of high-strength structural materials from iron tailings[J]. New Building Materials, 03: 4-6.

14. Li D. (2010)Preparation of high-strength concrete material with large amount of iron tailings[J]. Metal Mine, 02:167-170.

15. Wang A. (2013)Study on the activity of iron tailings powder used as concrete admixtures[J]. Concrete World, 000(008): 66-69.

16. Li B. (2015)Study on the preparation and performance of cascade grinding of iron tailings-phosphorus slag-based composite mineral admixture[J]. Bulletin of the Chinese Ceramic Society, 09: 7-13.

17. Piao C. (2016)The effect of chemical-mechanical coupling on the gelling activity of iron tailings powder[J]. Journal of Applied Basic Science and
Engineering, 06:31-40.

18. Feng X. (2007)Study on the optimization mechanism of iron tailings activity[J]. Modern Mining, 23(006): 21-24.

19. Yi Z. (2009)The effect of thermal activation on the gelling activity of iron tailings[J]. Journal of Wuhan University of Technology, 031(012): 5-7.

20. Li B. (2013)The effect of curing system on the activity of silicon-rich iron tailings powder and its slurry structure [J]. Journal of Wuhan University of Technology, 35(008):1-5.

21. Song A. (2015)Research on kaolinite-type pyrite beneficiation tailings as cement active admixtures[J]. Concrete and Cement Products, 09: 96-98.

22. Cheng Y. (2019)The effect of high-silicon iron tailings on concrete carbonation and sulfate corrosion resistance $[\mathrm{J}]$. Journal of Northeastern University (Natural Science Edition), 40(01): $124-128+152$.

23. Cheng Y. (2016)Test research on the effects of mechanochemically activated iron tailings on the compressive strength of concrete $[\mathrm{J}]$.Construction and Building Materials, 118: 164-170.

24. Zeng W. (2015)Research on the performance of iron tailings-based composite admixture concrete[J]. Concrete, 10: 78-81

25. Piao C. (2016)The influence of iron tailings powder on the durability of concrete[J]. Bulletin of the Chinese Ceramic Society, 35: 3295-3300.

26. Zhao S, Fan J, Sun W. (2014)Utilization of iron ore tailings as fine aggregate in ultra-high performance concrete $[\mathrm{J}]$. Construction and Building Materials, 50:540-548. 